ISAHP 2005, Honolulu, Hawaii, July 8-10, 2005

\title{
USING FAHP TO EVALUATE NON-STORE RETAILING CHANNEL ALTERNATIVES
}

\author{
Mei-Fang Chen ${ }^{1}$ \\ Department of Business Management, Tatung University \\ 40, Chung-Shan North Road, Sec. 3, Taipei, Taiwan \\ e-mail: mfchen@ttu.edu.tw
}

\begin{abstract}
Keywords: fuzzy analytic hierarchical process (FAHP), fuzzy multiple criteria decision-making (FMCDM), non-store retailing channel

Summary: Past studies pointed to the fact that consumers associate a higher level of risk with non-store shopping than in-store shopping. However, with the advent of the information technology and e-commerce, shoppers are now increasingly likely to shop across multiple channels. Multi-channel integration continues to be a focus and will be a key factor driving growth onward. This paper describes the Fuzzy Analytic Hierarchical Process (FAHP) to determine the weights of the perceived benefits and risks of various non-store retailing channels in a Fuzzy Multiple Criteria Decision-Making (FMCDM) environment and then to evaluate the performance of those alternatives. We find that the importance of non-store retailing channel decision-making main-dimension can be ranked in the sequence of price, merchandise, information service, purchasing atmosphere, convenience, and perceived risks. Consequently, the ranking order of the synthetic performance values of the non-store retailing channels obtained in this case is online shopping, TV home shopping, catalog shopping, newspaper shopping, and broadcasting shopping.
\end{abstract}

\section{Introduction}

The consumer behavior literature indicates that consumers associate various types of risks with purchase behavior, including functional, physical, financial, social, and psychological risks (Derbaix, 1983). However, the amount of these risks varies with shopping modes, e.g., in-store versus non-store shopping (Gillette, 1976; Spence, Engel and Blackwell, 1970). Consumers tend to display significantly higher levels of perceived risk when purchasing products by non-store means (e.g., through catalogs, direct mail, telephone, and door-to-door salespeople) than by in-store means (e.g., through a department store) (Spence, Engel and Blackwell, 1970). Thus, for direct marketers, the challenge is to evolve risk-reduction features that are effective in ameliorating the higher than average level of risks consumers associate with non-store shopping.

With the advent of information technology and e-commerce, the paradigm of retailing is dramatically changing, and we believe that direct marketing is playing a pivotal role. The most notable trend in recent years is that most retailers are hedging their bets across multiple mediums and consumers are taking advantage of this by supporting each of the channels. The retail environment is now being transformed with the introduction of multi-channel operations designed to offer a spectrum of retail experience for consumers to choose (Mathwick, Malhotra and Rigdon, 2001). Retailers redefine themselves as a source of memories rather than goods, as an "experience stager" rather than a service provider in such an emerging "Experience Economy" (Pine and Gilmore, 1999, p.12). Thus, how consumers choose non-store retailing channels needs to be further studied to propose an enhanced integrated marketing communication strategy.

${ }^{1}$ Corresponding author: Mei-Fang Chen; e-mail: mfchen@ttu.edu.tw 
From the viewpoint of the consumer, the choice of non-store retailing channels characterized by numerous factors must be considered and evaluated in terms of many different criteria, resulting in a vast body of data that are often inaccurate or uncertain. When people encounter uncertain or vague decision-making problems in the real world, they often employ a natural language to express their thinking and subjective perception instead of opting for accurate probability theory and statistics. Thus, fuzzy numbers and the context of the fuzzy set are introduced to appropriately express linguistic variables. The purpose of this study is to examine consumers' perception evaluation of different non-store retailing channels and to enhance their perceptions of value associated with the retail experience. The author focuses on how consumers make a decision based on their subjective judgment when they are in Fuzzy Multiple Criteria Decision-Making (FMCDM) environment. The Fuzzy Analytic Hierarchy Process (FAHP), which determines the weighting of subjective judgment, is selected to develop a scientific evaluation framework for the evaluation of non-store retailing channels.

\section{Evaluation Factors of Non-store Retailing Channels}

With the advent of the Internet revolution, which allows consumers to interact directly with producers (Ghosh, 1998), direct mail businesses and catalog retailers have survived and thrived during a period of intense and heightened cross-channel competition. Since a mix of selling channels and communication methods is often more efficient than any single-channel, single-method system (Moriarty and Moran, 1990), the hybrid channel is adopted by means of focusing and using of database marketing methods. The spread of satellite and cable television has turned the TV shopping industry into one of the best performers in direct marketing. Consumers can often get a better idea of what they are buying by tuning into a shopping show. In addition, an increasing number of customers shopping online because the Internet has the capability of providing a direct interactive shopping channel that is not bounded by time or geography. The emergence of the TV and electronic shopping has threatened the catalog retailing companies; however, these new channels also offer opportunities for them to increase their market share in the overall home shopping market (Morganosky and Fernie, 1999).

Online purchasing has become one of the most rapidly growing forms of shopping that has outpaced traditional retailing (Levy and Weitz, 2001). Mahajan and Wind (1989) consider the Web as a "market discontinuity," which co-exists and competes with traditional marketplaces. Consumers use the Web as the shopping intermediary for various reasons. Zeithaml, Parasuraman and Malhotra (2002) find that the consumers' motivations for online shopping are convenience, low price, and ease of shopping comparison. However, they contend that consumers might go offline to make the final purchase out of the concern for privacy and security of personal information. Mathwick, Malhotra and Rigdon (2002) test the effect of surface-depth congruence in an Internet and catalog setting to uncover value-based perceptions as retail performance indicators. These perceived values include visual appeal, entertainment value, escapism, intrinsic enjoyment, efficiency, economic value, and excellence. Srijumpa, Speece and Paul (2002) find that customers prefer the technology-based service as a better alternative for the following reasons: real-time, money-saving, flexible timeframe, sales personnel avoidance, and broader information coverage. Eastlick and Liu (1997) measure the importance of 24 assigned attributes, which represents a five priori categories: price, merchandise, retailer atmosphere/entertainment, selling service, and general service characteristics. After reviewing the related literature, we come to the conclusion that the following six distinct aspects influence the consumers to decide which non-store retailing channels they will choose.

(1) Price: The issue of low prices or money-savings has been associated with the trial and adoption of non-store shopping environments (Berkowitz, Walton and Walker, 1979; Korgaonkar, 1984; McDonald, 1993; Srijumpa , Speece and Paul, 2002; Zeithaml, Parasuraman and Malhotra, 2002). In general, consumers assume that the operating costs of a pure-player must be lower than that of traditional bricks and mortar with small promotion costs; thus, they expect that buying from the Internet could save money. Eastlick and Liu (1997) further indicate that not only low price is important but competitive prices, good markdowns, and value for price, are also important.

(2) Merchandise: Empirical studies on the importance to consumers of various attributes associated with non-store shopping suggest that consumers may use non-store shopping to gain access to greater merchandise assortments (McDonald, 1993; Reynolds, 1974), fashionability (Seitz, 1987), uniqueness (Kubes, 1981), and desired brands (Seitz, 1987). Eastlick and Liu (1997) further indicate that whether 
or not the non-store retailers can provide popular brand names, wide selection, quality merchandise, dependable products, fashionable styles are important indicators.

(3) Retailer atmosphere: In terms of shopping motivation, consumers are either "intrinsically motivated" that look for valued outcome or "fan, fantasy, arousal, sensory stimulation, and enjoyment" driven that look for hedonic experience (Hirschman and Holbrook, 1982). Thus, sometimes consumers who approach retail environments to browse (Bloch, Sherrell and Ridgway, 1986) or enjoy the experiential aspects of shopping (Bellenger and Korgaonkar, 1980; Lumpkin and Hawes, 1985) are motivated by the process rather than by shopping goals or outcome (Hoffman and Novak, 1996). Here, we evaluate whether or not the non-store retailing channel is entertaining, interesting, pleasant, exciting place/way in which to shop in the purchasing atmosphere aspect. Moreover, by providing information about its product or service by catalog or Internet or other impersonal medium, non-store retailing companies can engage the consumer in a comfortable atmosphere without the pressure of a pushy salesperson (Akaah, Korgaonkar and Lund, 1995).

(4) Information service: With the advent of information technology, consumers could search for and acquire broader information coverage at a very low cost in digital environments (Kalakota and Whinston, 1996; Srijumpa, Speece and Paul, 2002). Consumers also can do brand comparisons easily with the help of intelligent "infomediary" agents (Maes, 1999; Zeithaml, Parasuraman and Malhotra, 2002). Thus, the information that the non-store channel provides should be knowledgeable and helpful. The information presentation style is also important. Moreover, the product that the non-store channel recommends should have a popular or likeable spokesperson. Especially, in TV shopping, sometimes the salesperson in TV program is also very important (Eastlick and Liu, 1997).

(5) Convenience: Non-store shoppers are generally described as having a high convenience orientation (Berkowitz, Walton and Walker, 1979; Eastlick and Feinberg, 1994; Gehrt and Carter, 1992; Korgaonkar, 1984; Srijumpa, Speece and Paul, 2002; Zeithaml, Parasuraman and Malhotra, 2002) through various methods, such as telephone, mail order catalogue, electronic media and door-to-door sales to gain real time and flexible timeframe (Gehrt, Ingram and Howe, 1991). Convenience is expected to influence the adoption of online environments as manifested by the opportunity to shop at home $24 \mathrm{hr} / 7$ days a week (Hofacker, 2001) in this increasingly time-constrained world (Bhatnagar, Misra and Rao, 2000). Bellman, Lohse and Johnson (1999) also find that experienced and time-starved users of the Internet are more likely to make purchases online. In addition, services associated with delivery time, satisfaction with handling complaints and problems, and order placement have also been identified as being important to non-store shoppers (Klassen and Glynn, 1992). Here we evaluate the convenience in terms of whether the non-store retailing channel has a good return policy, accepts credit cards, offers convenient shopping hours, extends a quick way to locate products, make quick deliveries or not.

(6) Perceived Risks: Perceived risk is a useful context to explain barriers to online shopping (Forsythe and Shi, 2003). Although the risk associated with direct marketing might be reduced through the offer of risk relievers, the need to examine products before purchase remains strong for some consumers (Akaah, Korgaonkar and Lund, 1995). Zeithaml, Parasuraman and Malhotra (2002) indicate that the motivation to go offline is the preference for physical product interaction, service, privacy, and security of personal information. Stark and Meier (2001) reveal that the major reasons for the consumers not to purchase through the Internet are a fear of providing personal information, fear of an unfamiliar company, and fear of not receiving the product. The barriers of not purchasing through the Internet consist in the lack of trust regarding the security of online shopping and the lack of trust regarding the reliability of businesses on the Web (Hoffman and Novak, 1997; Keen, 1997). Thus, the need to examine products before purchase is a perceived risky element; in addition, the consumers' fear of an unfamiliar company, fear of not receiving the product, fear of not receiving the retailer's claimed products, fear of providing personal information are also included in the perceived risk factor.

\section{Fuzzy Analytic Hierarchy Process and Evaluation Methods}

The Analytic Hierarchy Process (AHP) developed by Saaty (1980) is a robust and easy to implement decision-making approach, by which one can develop the relative preferences or priorities of some given criteria and learn how well the alternatives score on these criteria. The method that considers both qualitative and quantitative information and combines them by decomposing unstructured problems into systematic hierarchies to rank alternatives based on a number of criteria has been extensively applied, especially in large-scale problems where many criteria must be considered and where the evaluation of alternatives is mostly subjective. 


\subsection{Building a Hierarchical System for Non-store Retailing Channels Evaluation}

Through the literature review, we set up a hierarchical system of non-store retailing channels for analysis and evaluation. Then we consider six aspects and twenty-nine criteria for achieving the overall goal to choose an ideal non-store retailing channel, as shown in Figure 1. All considered criteria are to be measured by different viewpoints evaluators.

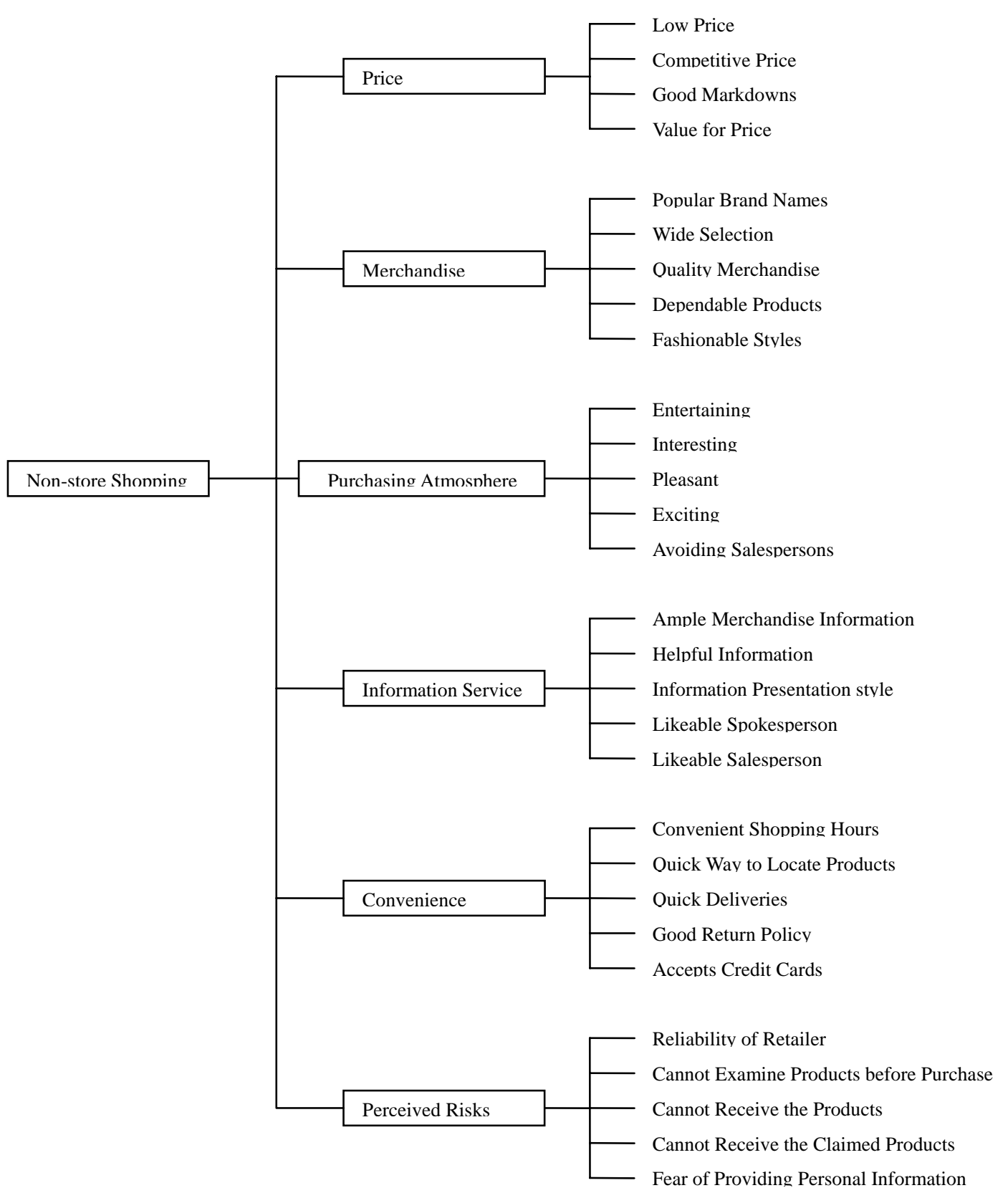

Figure 1. Hierarchical System for Non-store Retailing Channels Evaluation

\subsection{Fuzzy Number and Linguistic Variables}

Since fuzzy set theory was introduced by Zadeh (1965) and subsequently expanded by Bellman and Zadeh (1970), who described the decision-making methods in fuzzy environments, an increasing number of studies have dealt with uncertain fuzzy problems by applying fuzzy set theory. Because consumers often cannot clearly estimate the relative importance of each considered criterion in terms of numerical values, fuzziness as we mentioned earlier is applicable. Thus, this paper includes fuzzy 
decision-making theory, which considers the possible fuzzy subjective judgment during the evaluation process. We use triangular fuzzy numbers (TFN) in the fuzzy AHP to derive the relative importance for each criterion of non-store retailing channel choice, and the performance value for each criterion of each choice can also be determined by evaluators. After the synthetic performance values of alternatives are derived, then we rank the alternatives based on the best non-fuzzy performances (BNP). We introduce brief notions about fuzzy numbers and linguistic variables below.

A fuzzy number, $\tilde{A}$, is a fuzzy subset of a real number, and its membership function is $\mu_{\tilde{A}}(x)$ : $R \rightarrow[0,1]$, where $x$ represents the criteria, and it is described by the following characteristics (Dubois and Prade, 1978): (1) $\mu_{\tilde{A}^{(x)}}$ is a continuous mapping from $R$ to the closed interval [0,1]; (2) $\mu_{\left.\tilde{A}^{(}\right)}$ is a convex fuzzy subset; (3) $\mu_{\tilde{A}}(x)$ is the normalization of a fuzzy subset, which means that there exists a number $x_{0}$ such that $\mu_{\tilde{A}}\left(x_{0}\right)=1$. According to the characteristics of triangular fuzzy numbers and the extension principle put forward by Zadeh (1975), the operational laws of two triangular fuzzy numbers could be derived easily.

Moreover, conventional quantification is hard to express reasonably those situations that are overtly complex; thus the notion of a linguistic variable is necessary in such situations (Zadeh, 1975). A linguistic variable is a variable whose values are words or sentences in a natural or artificial language. We use this kind of expression to compare two evaluation criteria by linguistic variables in a fuzzy environment as "absolutely important," "very strongly important," "essentially important," "weakly important," and "equally important" with respect to a fuzzy five-level scale to derive the relative importance of the criteria. It is consistent with Saaty’s (1980) suggestion that the comparisons of the criteria be made in the range of 1/9 to 9 . A 9 indicates that one criterion is extremely more important than the other; a 1/9 indicates that one criterion is extremely less important than the other; and a 1 indicates equal importance. Also, if the importance of one criterion with respect to a second is given then the importance of the second criterion with respect to the first is the reciprocal. These pair-wise comparisons are summarized in a pair-wise comparison matrix. Furthermore, linguistic variables are also used as a way to measure the performance value of alternatives for each criterion as "very low," "low," “fair," "high," and "very high”. In this paper we employ triangular fuzzy numbers (TFN) to express the fuzzy scale.

\subsection{Fuzzy Weights and Synthetic Performance Values for Analytic Hierarchy Process}

Saaty (1980) originally introduced the Analytic Hierarchy Process (AHP) to systematically cope with complex problems in social systems. For this, he used the principal eigenvector of the comparison matrix to find comparative weights among the criteria of the hierarchical systems. If we wish to compare a set of $n$ criteria pair-wise according to their relative importance (weights), then we denote the criteria by $C_{1}, C_{2}, \ldots, C_{n}$, and their weights by $w_{1}, w_{2}, \ldots, w_{n}$. If $w=\left(w_{1}, w_{2}, \ldots, w_{n}\right)^{T}$ is given, the pair-wise comparisons may be represented by matrix $\boldsymbol{A}$ of the following formulation:

$\left(A-\lambda_{\max } I\right) w=0$

Eq.(1) denotes that $\boldsymbol{A}$ is the matrix of pair-wise comparison values derived by intuitive judgment for ranking order. Because an evaluator always perceives the weight with his own subjective evaluation, so an exact weight for a specified criterion is not given. This leads to the use of the fuzzy weights for criteria. Buckley (1985) was the first to investigate fuzzy weights and fuzzy utility for AHP technique, extending AHP by the geometric mean method to derive the fuzzy weights. Buckley (1985) considered a fuzzy positive reciprocal matrix $\tilde{A}=\left[\tilde{a}_{i j}\right]$, extending the geometric mean technique to define the fuzzy geometric mean of each row $\tilde{r}_{i}$ and fuzzy weight $\tilde{w}_{i}$ corresponding to each criterion as follows

$\tilde{r}_{i}=\left(\tilde{a}_{i 1} \otimes \cdots \otimes \tilde{a}_{i n}\right)^{1 / n} ; \tilde{w}_{i}=\tilde{r}_{i} \otimes\left(\tilde{r}_{1} \oplus \cdots \oplus \tilde{r}_{n}\right)^{-1}$

The result of fuzzy synthetic decisions reached by each alternative is a fuzzy number. Therefore, it is necessary to use the nonfuzzy ranking method for fuzzy numbers for comparison of the alternatives. In previous works the procedure of defuzzification has been to locate the best nonfuzzy performance (BNP) value. The three primary methods to defuzzify fuzzy rankings are mean of maximal, center of area (COA), and $\alpha$-cut (Zhao and Govind, 1991). Of these, the COA method to determine the BNP is simple and practical, and there is no need to introduce the preferences of any evaluators. We use the COA method in this paper to rank the order of importance of each criterion. The BNP value of the 
triangular fuzzy number $\left(L R_{i}, M R_{i}, U R_{i}\right)$ can be found by the following equation; according to the value of the derived BNP, the ranking evaluation of each alternative can be obtained.

$$
B N P_{i}=\left[\left(U R_{i}-L R_{i}\right)+\left(M R_{i}-L R_{i}\right)\right] / 3+L R_{i}, \forall i
$$

\section{Illustration}

Below we provide an illustrative example of non-store retailing shopping evaluation in Taiwan to demonstrate that the fuzzy AHP provides a good evaluation and appears to be more appropriate in the fuzzy MCDM environment of human subjective judgment. There are three subsections: (1) problem description, (2) application for the fuzzy AHP in a fuzzy MCDM environment, and (3) discussion.

\subsection{Problem Description}

There are many challenges for direct marketing in a concentrated retail market such as Taiwan. Some unique challenges to in-home retailing here include the small geographical size, easy access to neighborhood and planned shopping centers, distrust of the direct marketer as well as the prices and quality of merchandise offered through in-home methods, the non-generous merchandise return and refund policy practiced by retailers in general. Therefore, the actual sales through direct marketing are negligible and restricted to the more affluent, educated, and cosmopolitan segments of the population. As a result, there are very few retailers who are targeting in-home shoppers locally. However, ET Mall, founded in late 1999, is the most profitable and the largest home shopping channel in Taiwan. This large Taiwanese multi-media consumer goods marketer integrates five different shopping media (TV, catalogues, newspaper, websites, and broadcasting) in selling its products. The advent of the information technology and e-commerce revolution is one of the major reasons, and the other important reason is that the consumers are adopting the hybrid /or multi-channel shopping strategy. To understand how the consumers choose the non-store shopping channel and to enhance the retailer's integrated marketing communication strategy is an important task for direct marketers and other traditional brick-and-mortar retailers.

\subsection{Determining of Evaluation Criteria Weights and the Performance Matrix}

Based on the AHP hierarchical framework for non-store retailing channel evaluation criteria that we have set up in Section 3.1, we measure the 29 criteria in the hierarchical model as data input, and then use fuzzy MCDM to evaluate each alternative and make a selection. We give an empirical study in Taiwan as an example to show the practicability and usefulness of the proposed method through 20 non-store retailing shoppers who had taken the course(s) of marketing management and/or consumer behavior in the EMBA curriculum in a university. Among these 20 shoppers, 12 are male and 8 are female. These non-store retailing shoppers are operationally defined as those who had made at least one non-store purchase experience by Internet and/or catalog and/or TV and/or newspaper and/or broadcasting during the past one year. Based on their own purchasing experiences and subjective perceptions of these various non-store shopping channels, we then derive the final fuzzy weights and non-fuzzy BNP values corresponding to each criterion, as shown in Table 1.

The evaluators can define their own individual range for the linguistic variables employed based on their subjective judgments within a fuzzy scale to determine the performance value of each alternative. Let $\tilde{h}_{i j}{ }^{k}$ represent the fuzzy performance score by the $k$-th evaluator of the $i$-th non-store retailing channel under the $j$-th criterion. We employ the fuzzy geometric mean method to integrate the fuzzy performance score $\tilde{h}_{i j}$ for $m$ evaluators. This is,

$$
\tilde{h}_{i j}=\left(\tilde{h}_{i j}{ }^{1} \otimes \cdots \otimes \tilde{h}_{i j}{ }^{m}\right)^{1 / m}
$$

Furthermore, we employ the COA defuzzification procedure to compute the BNP values of fuzzy performance score $\tilde{h}_{i j}$. The fuzzy performance scores of various non-store retailing channels with respect to the criteria and the BNP values are shown in Table 2. It appears that the ranking order of the overall synthetic performance values (based on the 29 criteria) of the non-store retailing channel alternatives (see the bottom line of the table) is the online shopping, TV home shopping, catalog shopping, newspaper shopping, and broadcasting shopping. 
Table 1 Criteria Weights and Aspects for Non-store Shopping Channels

\begin{tabular}{|c|c|c|c|}
\hline Aspect/Criterion & & Weight & Total Weights $\left(W_{j}\right)$ \\
\hline Price & 0.2518 & $(0.1780,0.2465,0.3309)$ & \\
\hline Low price & 0.2607 & $(0.1720,0.2501,0.3598)$ & $0.0704(0.0306,0.0617,0.1191)[5]$ \\
\hline Competitive price & 0.2499 & $(0.1696,0.2414,0.3387)$ & $0.0672(0.0302,0.0595,0.1121)[6]$ \\
\hline Good markdowns & 0.2705 & $(0.1843,0.2588,0.3682)$ & $0.0728(0.0328,0.0638,0.1218)[3]$ \\
\hline Value for price & 0.2621 & $(0.1735,0.2497,0.3630)$ & $0.0708(0.0309,0.0616,0.1201)[4]$ \\
\hline Merchandise & 0.2474 & $(0.1741,0.2403,0.3279)$ & \\
\hline Popular brand names & 0.1893 & $(0.1260,0.1800,0.2617)$ & $0.0503(0.0219,0.0433,0.0858)[10]$ \\
\hline Wide selection & 0.1197 & $(0.0808,0.1142,0.1642)$ & $0.0318(0.0141,0.0274,0.0538)[13]$ \\
\hline Quality merchandise & 0.1983 & $(0.1329,0.1899,0.2721)$ & $0.0527(0.0231,0.0456,0.0892)[9]$ \\
\hline Dependable products & 0.3278 & $(0.2202,0.3156,0.4477)$ & $0.0870(0.0383,0.0758,0.1468)[1]$ \\
\hline Fashionable styles & 0.2084 & $(0.1382,0.2002,0.2869)$ & $0.0554(0.0241,0.0481,0.0941)[8]$ \\
\hline Retailer atmosphere & $\underline{0.1132}$ & $(0.0800,0.1087,0.1508)$ & \\
\hline Entertaining & $\frac{3.1508}{0.1508}$ & $(0.0970,0.1442,0.2112)$ & $0.0184(0.0078,0.0157,0.0319)[29]$ \\
\hline Interesting & 0.1850 & $(0.1204,0.1780,0.2564)$ & $0.0226(0.0096,0.0194,0.0387)[23]$ \\
\hline Pleasant & 0.2048 & $(0.1353,0.1959,0.2831)$ & $0.0249(0.0108,0.0213,0.0427)[18]$ \\
\hline Exciting & 0.2276 & $(0.1493,0.2156,0.3179)$ & $0.0278(0.0119,0.0234,0.0480)[15]$ \\
\hline Avoiding salespersons & 0.2807 & $(0.1813,0.2662,0.3948)$ & $0.0343(0.0145,0.0289,0.0595)[12]$ \\
\hline Information service & $\underline{0.2210}$ & $(0.1557,0.2136,0.2935)$ & \\
\hline Ample merchandise information & $\frac{0.210}{0.3611}$ & $(0.2372,0.3481,0.4978)$ & $0.0858(0.0369,0.0744,0.1461)[2]$ \\
\hline $\begin{array}{l}\text { Helpful information } \\
\text { Hercin }\end{array}$ & 0.2744 & $(0.1778,0.2630,0.3824)$ & $0.0654(0.0277,0.0562,0.1123)[7]$ \\
\hline Information presentation style & 0.1869 & $(0.1239,0.1778,0.2590)$ & $0.0444(0.0193,0.0380,0.0760)[11]$ \\
\hline Likeable spokesperson & 0.1282 & $(0.0839,0.1202,0.1805)$ & $0.0306(0.0131,0.0257,0.0530)[14]$ \\
\hline Likeable salesperson & 0.0969 & $(0.0645,0.0908,0.1353)$ & $0.0231(0.0100,0.0194,0.0397)[21]$ \\
\hline Convenience. & $\mathbf{0 . 1 0 1 1}$ & $(0.0716,0.0967,0.1349)($.0500, 0.1330$)$ & \\
\hline Convenient shopping hours & 0.1725 & $(0.1150,0.1639,0.2385)$ & $0.0188(0.0082,0.0158,0.0322)[28]$ \\
\hline Quick way to locate products & 0.2335 & $(0.1493,0.2221,0.3292)$ & $0.0255(0.0107,0.0215,0.0444)[17]$ \\
\hline Quick deliveries & 0.2085 & $(0.1337,0.1981,0.2939)$ & $0.0228(0.0096,0.0191,0.0396)[22]$ \\
\hline Good return policy & 0.1864 & $(0.1193,0.1766,0.2632)$ & $0.0204(0.0085,0.0171,0.0355)[25]$ \\
\hline Accepts credit cards & 0.2485 & $(0.1647,0.2394,0.3415)$ & $0.0270(0.0118,0.0231,0.0461)[16]$ \\
\hline $\begin{array}{l}\text { Perceived risks } \\
\text { Percics }\end{array}$ & $\mathbf{0 . 0 9 8 9}$ & $(0.0704,0.0942,0.1320)(0.2094,0.3415)$ & \\
\hline Reliability of retailer & $\frac{0.2256}{0.2256}$ & $(0.1514,0.2167,0.3086)$ & $0.0239(0.0107,0.0204,0.0407)[19]$ \\
\hline Cannot examine products before purchase & 0.1924 & $(0.1369,0.1862,0.2543)$ & $0.0202(0.0096,0.0175,0.0336)[27]$ \\
\hline Cannot receive the product & 0.2068 & $(0.1437,0.1995,0.2770)$ & $0.0218(0.0101,0.0188,0.0366)[24]$ \\
\hline Cannot receive the claimed products & 0.2204 & $(0.1566,0.2139,0.2908)$ & $0.0232(0.0110,0.0202,0.0384)\lceil 20]$ \\
\hline Fear of providing personal information & 0.1919 & $(0.1290,0.1837,0.2629)$ & $0.0204(0.0091,0.0173,0.0347)[26]$ \\
\hline
\end{tabular}

Table 2. Evaluation Results of Non-store Shopping Channels

\begin{tabular}{|c|c|c|c|c|c|}
\hline Aspect/Criterion & Online & Catalog & TV home & Newspaper & Broadcasting \\
\hline \multicolumn{6}{|l|}{ Price } \\
\hline Low price & $5.8004[1]$ & $3.9446[2]$ & $3.5770[3]$ & $3.4822[4]$ & $2.7025[5]$ \\
\hline Competitive price & $5.6916[1]$ & $3.9335[2]$ & $3.1187[4]$ & $3.4521[3]$ & $2.3996[5]$ \\
\hline Good markdowns & $5.1094[1]$ & $4.0130[2]$ & $3.9110[3]$ & $3.6557[4]$ & $3.1153[5]$ \\
\hline $\begin{array}{l}\text { Value for price } \\
\text { Pan }\end{array}$ & $4.7776[2]$ & $4.5426[3]$ & $5.0245[1]$ & $3.6763[4]$ & $2.5997[5]$ \\
\hline \multicolumn{6}{|l|}{ Merchandise } \\
\hline Popular brand names & 4.0994 [1] & $2.9923[3]$ & $3.1043[2]$ & $2.3096[4]$ & $1.6250[5]$ \\
\hline $\begin{array}{l}\text { Wide selection } \\
\text { Wintes }\end{array}$ & $2.6904[1]$ & $1.9276[2]$ & $1.8459[3]$ & $1.4555[4]$ & $0.9054[5]$ \\
\hline Quality merchandise & $3.3594[1]$ & $3.2426[3]$ & $3.2746[2]$ & $2.5373[4]$ & $1.7771[5]$ \\
\hline Dependable products & $5.6642[1]$ & $5.5971[2]$ & $5.5109[3]$ & $4.1632[4]$ & $2.8508[5]$ \\
\hline \multirow{2}{*}{\multicolumn{6}{|c|}{ Retailer atmosphere }} \\
\hline & & & & & \\
\hline Entertaining & $1.2565[2]$ & $1.0577[3]$ & $1.3791[1]$ & $0.8499[4]$ & $0.7625[5]$ \\
\hline Interesting & $1.7091[2]$ & $1.3657[3]$ & $1.7257[1]$ & $1.0631[4]$ & 0.9559 [5] \\
\hline $\begin{array}{l}\text { Pleasant } \\
\text { Plo }\end{array}$ & $1.8451[1]$ & $1.5653[3]$ & $1.7079[2]$ & $1.2988[4]$ & 1.1129 [5] \\
\hline Exciting & $2.0019[1]$ & 1.6154 [3] & $1.8374[2]$ & $1.2249[4]$ & 1.1028 [5] \\
\hline \multirow{2}{*}{\multicolumn{6}{|c|}{ Information service }} \\
\hline & & & & & \\
\hline Ample merchandise information & $7.2197[1]$ & $5.1615[3]$ & $5.8520[2]$ & $4.4844[4]$ & $3.1037[5]$ \\
\hline Helpful information & $5.6304[1]$ & $4.2579[3]$ & $4.6534[2]$ & $3.4166[4]$ & $2.7545[5]$ \\
\hline Information presentation style & $3.6523[1]$ & $3.0029[3]$ & $3.2065[2]$ & $2.1982[4]$ & $1.6337[5]$ \\
\hline $\begin{array}{l}\text { Likeable spokesperson } \\
\text { S syle }\end{array}$ & $1.6110[3]$ & $1.7304[2]$ & $2.1665[1]$ & $1.5509[4]$ & 1.2778 [5] \\
\hline Likeable salesperson & $1.0688[3]$ & $1.0857[2]$ & 1.4344 [1] & $0.9680[4]$ & $0.9486[5]$ \\
\hline \multicolumn{6}{|l|}{ Convenience } \\
\hline Convenient shopping hours & $1.5994[1]$ & 1.2894 [2] & $1.2711[3]$ & $0.9945[4]$ & $0.8000[5]$ \\
\hline Quick way to locate products & $2.2288[1]$ & $1.6093[2]$ & $1.4094[3]$ & $1.0925[4]$ & $0.7677[5]$ \\
\hline Quick deliveries & $1.5025[2]$ & 1.4986 [3] & 1.6140 [1] & $1.1389[4]$ & 0.9688 [5] \\
\hline Good return policy & $1.1721[3]$ & $1.3727[2]$ & $1.4116[1]$ & $0.9603[4]$ & $0.7751[5]$ \\
\hline Accepts credit cards & $2.0400[3]$ & $2.1400[2]$ & $2.2024[1]$ & $1.6239[4]$ & $1.1384[5]$ \\
\hline \multicolumn{6}{|l|}{$\begin{array}{l}\text { Perceived risks } \\
\text { Pros }\end{array}$} \\
\hline Reliability of retailer & $1.4878[3]$ & $1.6784[2]$ & $1.7478[1]$ & $1.2170[4]$ & $0.8595[5]$ \\
\hline Cannot examine products before purchase & 0.4327 [3] & $0.5562[2]$ & $0.5577[1]$ & $0.4830[4]$ & 0.4152 [5] \\
\hline 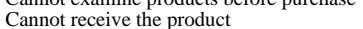 & $0.6142[3]$ & $0.8738[2]$ & $1.1698[1]$ & $0.6890[4]$ & $0.5651[5]$ \\
\hline Cannot receive the claimed products & 0.6316 [3] & $0.6484[2]$ & 0.8143 [1] & $0.6299[4]$ & 0.5147 [5] \\
\hline Fear of providing personal information & $0.3687[3]$ & $0.5685[2]$ & $0.6476[1]$ & $0.5261[5]$ & $0.5903[4]$ \\
\hline Total & $82.6087[1]$ & $69.6301[3]$ & $72.5418[2]$ & $56.4035[4]$ & $43.0740[5]$ \\
\hline
\end{tabular}

criterion.

\subsection{Discussion}

Table 1 indicates that the importance ranking of non-store retailing channel decision-making main-dimension is price $(0.2518)$, merchandise $(0.2474)$, information service $(0.2210)$, purchasing atmosphere (0.1132), convenience (0.1011), and perceived risks (0.0989). Based on the results, it is found that price is ranked as the most important factor among the six decision-making factors. In the price aspect, each of the criteria has almost equal importance and good markdowns is ranked in the first place. Merchandise is ranked in the second place, dependable products plays the most important role in this aspect. Fashionable styles, quality merchandise, and popular brand names take on almost equal importance, and wide selection is the least important criterion in this aspect. Information service is ranked in the third place, ample merchandise information and whether the information is helpful or not are important determinant criteria; on the contrary, a helpful salesperson is not important at all. 
The most important criterion in the retailer atmosphere is that the non-store retailing channel could avoid the salesperson's pressure. As for the hedonic value, an exciting and pleasant atmosphere is also important. Surprisingly, convenience is not as important as generally believed. One of the possible explanations is that the small geographical size such as Taiwan offers easy access to neighborhood and planned shopping centers. Thus, convenience is not as important as previous studies show. However, whether the non-store shopping channel accepts the credit card, whether there is a quick way to locate products, and whether deliveries are quick are still important determinants in the convenience aspects. Finally, the perceived risk is the least important factor for non-store shoppers, indicating that the risk relievers the non-store retailer's provide do exert influence on consumers. Moreover, the reliability of the non-store retailers plays the most important role in this aspect. As for the importance of the other four decision-making criteria in the perceived risk aspect, they are almost the same.

When we consider all these 29 evaluation criteria, we find that dependable products, ample merchandise information, and good markdowns are the most important three decision-making elements. It means that dependable product is everything that the non-store retailers should focus. The least important three decision-making elements are whether the non-store shopping channel is entertaining or not, whether the shopping hours is convenient or not, and whether customers can examine products before purchase. The results further verify that the consumers make use of the non-store shopping channels not because of convenience, and they are not worried about whether they can examine the products before purchase or not, either. Moreover, they do not purchase from non-store shopping channel just for entertainment.

Consequently, the ranking order of the synthetic performance values of the non-store retailing channels obtained in this study is online shopping, TV home shopping, catalog shopping, newspaper shopping, and broadcasting shopping (see Table 2). But the synthetic performance value of the item ranks first (online shopping, 82.6087) is much higher than that of the item ranks second (TV home shopping, 72.5418); and the gap between the items rank second and third (catalog shopping, 69.6301) is much smaller. The synthetic performance values of newspaper shopping and broadcasting shopping are even smaller than 60 . The results prove that the online shopping is really prevalent right now. It is also worthy of notice that the performance scores of online shopping in the merchandise factor is the highest but only modest in the perceived risks factor.

On the contrary, the synthetic performance value of TV home shopping is ranked first in the perceived risks factor, meaning that the consumers think the perceived risk of this non-store retailing channel is the lowest. Moreover, TV home shoppers provide the products with good financial support (the retailers often accept installment by credit card in Taiwan) in addition to perceived value for price. It is also an entertaining and interesting way to shop with a good return policy and quick delivery service. No wonder, TV home shopping continues to grow quite rapidly. The synthetic performance value of broadcasting shopping is ranked at the bottom and newspaper shopping is found to rank at the second place from the bottom. Perhaps the consumers treat newspaper and broadcasting more as traditional communication tools than for their shopping functions.

\section{Conclusion}

The primary impetus behind the growth of non-store retailing is the automation of direct marketing practices made possible by information technology. Technological advances and innovations not only change the way that retailers interact with their customers but also alter shoppers' custom of buying merchandise from them. Shoppers are now increasingly likely to shop across multiple channels. Even traditional brick-and-mortar retailers are also beginning to complement their operations with catalogs, an on-line presence, or both. Multi-channel integration continues to be a focus and will be a key factor driving forward-moving growth. Thus, non-store retailers should understand the perceived benefits and risks of various non-store retailing channels to enhance an effective integrated marketing communication strategy. From the results of a practical application in evaluating the non-store retailing channel decision-making, the proposed method makes an effective evaluation and appears to be the most appropriate in a fuzzy environment. 


\section{References:}

Akaah, I. P., Korgaonkar, P. K. and Lund, D. (1995), “Direct Marketing Attitudes,” Journal of Business Research, 34, 211-219.

Bellenger, D. N. and Korgaonkar (1980), “Profiling the Recreational Shopper,” Journal of Retailing, 56, 77-92.

Bellman, R. E. and Zadeh, L. A. (1970), “Decision Making in a Fuzzy Environment,” Management Science, 17, 141-164.

Bellman, S., Lohse, G. L. and Johnson, E. J. (1999), "Predictors of Online Buying behavior," Communications of the Association for Computing Machinery, 42, 32-38.

Berkowitz, E. N., Walton, J. R. and Walker, O. C. (1979), "In-home Shoppers: The Market for Innovative Distribution Systems,” Journal of Retailing, 55, 15-33.

Bhatnagar, A., Misra, S. and Rao, H. R. (2000), “On risk, Convenience, and Internet Shopping Behavior,” Communications of the Association for Computing Machinery, 43, 98-105.

Bloch, P. H., Sherrell, D. L. and Ridgway, N. M. (1986), "Consumer Search: An Extended Framework,” Journal of Consumer Research, 13, 119-126.

Buckley, J. J. (1985), “Fuzzy Hierarchical Analysis,” Fuzzy Sets and Systems, 17, 233-247.

Derbaix, C. (1983), ”Perceived Risk and Risk Relievers: An Empirical Investigation, Journal of Economic Psychology, 3, 19-38.

Dubois, D. and Prade, H. (1978). “Operations on Fuzzy Numbers,” International Journal of Systems Science, 9, 613-626.

Eastlick, M. A. and Liu, M. (1997), “The Influence of Store Attitudes and Other Nonstore Shopping Patterns on Patronage of Television Shopping Programs," Journal of Direct Marketing, 11, 14-24.

Eastlick, M. A. and Feinberg, R. A. (1994), “Gender Difference in Mail Catalog Patronage Motives,” Journal of Direct Marketing, 8, 37-44.

Forsythe, S.M. and Shi, B. (2003), "Consumer Patronage and Risk Perceptions in Internet shopping," Journal of Business Research, 56, 867-875.

Gehrt, K. C. and Carter, K. (1992), “An Exploratory Assessment of Catalog Shopping Orientation,” Journal of Direct Marketing, 6, 29-39.

Gehrt, K. C., Ingram, T. N. and Howe, V. (1991), “Nonstore versus Store Retailing,” Journal of Direct Marketing, 5, 44-53.

Ghosh, S. (1998), “Making Business Sense of the Internet,” Harvard Business Review, 76, 126-135.

Gillette, P. (1976), “In-home Shoppers-An Overview,” Journal of Marketing, 40, 81-88.

Hirschman, E. C. and Holbrook, M. B. (1982), "Hedonic Consumption: Emerging Concepts, Methods and Propositions,” Journal of Marketing, 46, 92-101.

Hofacker, C. F. (2001). Internet Marketing, ( $3^{\text {rd }}$ ed.) New York: John Wiley \& Sons, Inc.

Hoffman, D. L. and Novak, T. P. (1996), "Marketing in Hypermedia Computer-mediated Environments: Conceptual Foundations,” Journal of Marketing, 60, 50-68.

Hoffman, D.L. and Novak, T.P., (1997), “A New Marketing Paradigm for Electronic Commerce,” The Information Society, Special Issue on Electronic Commerce, 13, pp. 43-54.

Kalakota, R., Andrew, B. and Whinston (1996). Frontiers of Electronic Commerce, Addison-Wesley.

Keen, P.G., (1997). “Future of the Internet Relies on Trust”, Computerworld, 31, p. 70.

Klassen, M. L. and Glynn, K. A. (1992), "Catalog Loyalty: Variables That Discriminate Between Repeat and Non-repeat Customers,” Journal of Direct Marketing, 6, 60-67.

Korgaonkar, P. K. (1984), “Consumer Shopping Orientations, Non-store Retailers, and Consumers' Patronage Intentions: A Multivariate Investigation,” Journal of the Academy of Marketing Science, 12, 
$11-22$.

Kubes, D. (1981), “Mail Order: Why Do People Buy?” Direct Marketing, 44 (October), 132-136.

Levy, M. and Weitz, B. A. (2001). Retailing Management. (4 ${ }^{\text {th }}$ ed.) New York, NY: McGraw-Hill.

Lumpkin, J. R. and Hawes, J. M. (1985), "Retailing without Stores: An Examination of Catalog Shopper,” Journal of Business Research, 13, 139-151.

Maes, P. (1999), “Smart Commerce: The Future of Intelligent Agents in Cyberspace,” Journal of Interactive Marketing, 13, 66-76.

Mahajan, V. and Wind, J. (1989), "Market Discontinuities and Strategic Planning: A Research Agenda,” Technological Forecasting and Social Change, 36, 185-199.

Mathwick, C., Malhotra, N. and Rigdon, E. (2001), "Experiential Value: Conceptualization, Measurement and Application in the Catalog and Internet Shopping Environment,” Journal of Retailing, 77, 39-56.

Mathwick, C., Malhotra, N. and Rigdon, E. (2002), “The Effect of Dynamic Retail Experiences on Experiential Perceptions of Value: An Internet and Catalog Comparison,” Journal of Retailing, 78, 51-60.

McDonald, W. J. (1993), "The Roles of Demographic, Purchase Histories and Shopper Decision-making Styles in Predicting Catalog Loyalty,” Journal of Direct Marketing, 7, 55-65.

Morganosky, M. A. and Fernie, J. (1999), "Mail Order Direct Marketing in the United States and the United Kingdom: Responses to Changing Market Conditions,” Journal of Business Research, 45, 275-279.

Moriarty, R. T., Moran, U. (1990), “Managing Hybrid Marketing Systems,” Harvard Business Review, 68, 146-155.

Pine B. J. and Gilmore, J. H. (1999). The Experience Economy: Work is theater \& Every Business A Stage, Boston, MA: Harvard business Press.

Reynolds, F. D. (1974), “An Analysis of Catalog Buying Behavior,” Journal of Marketing, 38, 47-51.

Saaty, T. L. (1980). The Analytic Hierarchy Process. McGraw-Hill: New York.

Seitz, V. (1987). Patronage Behavior of Nonusers, Users, and Heavy Users of Catalogs for Clothing Purchases. Unpublished PhD dissertation, Oklahoma State University.

Spence, H. E., Engel, J. F. and Blackwell, R. D. (1970), "Perceived Risk in Mail-order and Retail Store Buying,” Journal of Marketing Research, 364-369.

Srijumpa, R., Speece, M. and Paul, H. (2002), "Satisfaction Drivers for Internet Service Technology among Stock Brokerage Customers in Thailand,” Journal of Financial Services Marketing, 6, 240-253.

Stark, J. and Meier, R. (2001), “A Longitudinal Study of Usage and Satisfaction Levels of Internet Shopping by College Students,” Journal of Computer Information Systems, 41, 65-68.

Zadeh, L. A. (1965), “Fuzzy Sets,” Information and Control, 8, 338-353.

Zadeh, L. A. (1975), “The Concept of A Linguistic Variable and Its Application to Approximate Reasoning, Parts 1, 2, and 3. Information Science 8, 199-249, 301-357, 9, 43-80.

Zeithaml, V. A., Parasuraman, A. and Malhotra, A. (2002), "Service Quality Delivery Through Web Sites: A Critical Review of Extant Knowledge," Journal of the Academy of Marketing Science, 30, 362-375.

Zhao R and Govind, R. (1991), “Algebraic Characteristics of Extended Fuzzy Numbers,” Information Science, 54, 103-130. 